\title{
Group-Based Emotion In Group Processes and Intergroup Relations
}

Diane M. Mackie

University of California, Santa Barbara

Eliot R. Smith

Indiana University

20th Anniversary Special Issue

Group Processes and Intergroup Relations

5945 words including refs 


\section{Group-Based Emotion In Group Processes and Intergroup Relations}

\section{Introduction}

In the first article in the inaugural volume of Group Processes and Intergroup Relations, Abrams and Hogg (1998) predicted a positive trajectory for group related research. They did so based on analysis of articles about 71 key group-related topics in important empirical publication outlets between 1974 and 1996. Conspicuously absent from that list of group relevant topics was anything that smacked of affect - no group mood, no group emotions. Prejudice research made a made a strong showing, of course, but mainly as an attitudinal or evaluative perspective on groups.

As is so often the case, timing was everything. A key article foundational to thinking about emotion and group belonging (Smith, 1993) had appeared a few years earlier, but was not included because it was a theoretical contribution to an edited volume. Had the later consequences of this and related approaches on empirical contributions to the group literature been known, Abrams and Hogg's predicted trajectory might have been even more positive. Both the impact of group-based emotion on intra-group processes and the impact of emotion on intergroup relations have flourished over the last two decades, driven by theoretical and empirical demonstrations that emotions can be group-level, and not merely individual-level, phenomena.

We first review the transformative idea that emotion can occur as a group-level phenomena driven by group-level processes. We then very briefly review the impact of this idea on research about intragroup processes and intergroup relations in the decades since 1998. We conclude by raising some questions whose answers would further extend the reach and predictive power of group-based emotions in both intra-group and intergroup contexts.

\section{Emotions as Group Level Phenomena}

Interest in emotions as group level rather than merely individual processes has spawned multiple major research approaches. Intergroup emotion theory (for a comprehensive review see Mackie \& Smith, 2016) has documented the uniquely group-level nature of emotions that are experienced as a result of group categorization and group identification. A second program of research focuses on group-based emotions about specific events, arising from group-based appraisals influenced by a salient social identity (see Yzerbyt \& Kuppens, 2009, for a review). A third important line of research focuses on collective emotion, emotions shared because of membership in a collective or group (see Doosje, Branscombe, Spears, \& Manstead, 2006, for a review).

The research that has accumulated has definitively established that emotion can be a group-level phenomenon. First, social categorization into a group changes emotional experience. For example, when asked how much joy, fear, anger, and so forth they are 
feeling as individuals, people report both quantitatively and qualitatively different emotions than they report after a group membership has been activated. Activation can occur subtly, for example by exposure to songs, symbols, or sights associated with a university or national identity (Seger, Smith, \& Mackie, 2009; see also Moons, Leonard, Mackie, \& Smith, 2009). Activation of different group memberships within the same individuals also produces different emotional experiences. For example, the same participants report different emotions toward Muslims and toward the police when asked to "Think about yourself as an American" compared to "Think about yourself as a student” (Ray, Mackie, Rydell, \& Smith, 2008). Social categorization determines emotional experience.

Second, the processes that produce these emotions are group level processes. Considerable evidence supports the idea that group-based emotions are often triggered by group-based appraisal or construal processes. For example, when categorized as students, participants appraised a proposal to raise tuition at the University of Colorado for nonresidents of the state as more unjust than they did when categorized as Colorado residents (Gordijn, Yzerbyt, Wigboldus, \& Dumont, 2006). Thus appraisals of the same event were determined by group membership. Those group-based appraisals in turn underlay the greater anger towards the proposal felt by participants categorized as students rather than state residents (Gordijn et al., 2006). In other circumstances, groupbase emotions can be triggered more directly, through the activation of a group emotion norm. When individuals are given information about particular emotions that members of their groups are experiencing ("Women are angry over the candidate's latest comments ...”) they later report feeling the appropriate emotion when categorized into the appropriate group (Moons et al., 2009). This convergence toward the ingroup's assumed emotional experience occurred for positive and negative emotions and for national and gender groups, as well as for a laboratory-created minimal group. Even more indicative of the group-level processes underlying these effects, there was more adoption of the ingroup emotion when members were experimentally led to believe that they were somewhat different from the rest of their group, increasing their motivation to conform (see also Reyson \& Branscombe, 2008).

Finally, as with other group-level processes, the production and experience of groupbased emotion depends on an individual's level of identification with the group. First, identification moderates the extent to which group members share their in-group's emotion. Highly identified members most closely match the ingroup's emotional standard (Seger, Smith, Kinias, \& Mackie, 2009; Smith et al., 2007). For example, if a group allegedly feels anger, highly identified members not only report feeling more anger but are also more likely to show risky decision making, a well-established downstream consequence of anger (Moons et al., 2009). Second, identification with the group affects the intensity with which group-based emotions are experienced. This relationship depends on what the particular emotion means for the group. Emotions that reflect on the ingroup as positive or powerful (pride, satisfaction at success, schadenfreude, anger at threat or insult) are felt more strongly by the highly identified (Combs, Powell, Schurtz, \& Smith, 2009; Maitner, Mackie, \& Smith, 2007; Pennekamp, Doosje, Zebel, \& Fischer , 2007; Smith et al., 2007). Emotions that implicate the ingroup in wrongdoing, however, 
such as guilt at ingroup transgressions, are felt less strongly by high identifiers, at least in part because such individuals make positively biased group-based appraisals of the events (Kuppens \& Yzerbyt, 2014; Maitner et al., 2007).

\section{Group-based Emotions in Intragroup Processes}

Accepting that emotions can be group level rekindled interest in the role of emotional processes within the group. This re-energization owed much to Barsade and Gibson's (1998) demonstration that an emotional state could pervade, and thus become dominant in, an interacting group, thus shaping a wide variety of intragroup processes (Barsade \& Knight, 2016; Knight, \& Eisenkraft, 2015). Predominant explanations focused on emotion contagion and vicarious emotion sharing, processes that rely on some form of direct interaction and mimicry based on perceiving facial expressions, vocal tone, and so forth. Although these are not themselves group-level processes, it is clear that group level processes can moderate them. For example, emotional mimicry and vicarious emotion learning occur much more readily among ingroup members (see Smith \& Mackie, 2016) and among group members who identify strongly with the group (Ilies, Wagner, \& Morgeson, 2007). At the same time, the role of more clearly group-based emotion processes, particularly emotional self-stereotyping and emotional normative influence, offer complementary explanations for group emotion sharing that can occur even in widely distributed, non-interacting groups (Moons et al., 2009). For example, Thomas, McGarty, \& Mayor (2009) consider the transmission of injunctive emotion norms essential for group commitment, and group emotion norms depend crucially on shared appraisals based on a group’s goals (Fischer, Manstead, \& Zaalberg, 2003).

Group emotions have two clear consequences for intragroup processes. First, shared group emotion is essential to what Mengus and Kilduff (2015) refer to as the viability of groups - affiliative and commitment processes that allow new groups to emerge and established groups to survive (see Barsade \& Knight, 2015; Mengus \& Kilduff, 2015; Niedenthal \& Brauer, 2012, for reviews). For example, the experience of shared emotion, even negative, can trigger group formation and promote social integration (Barsade \& Gibson, 2012; Knight \& Eisenkraft, 2015; Walter \& Bruch 2008). When individuals are unable to share a group emotion, they believe they do not belong to the group (Livingstone, Spears, Manstead, Bruder, \& Shepherd, 2011). Whereas the shared similarity of intragroup emotion enhances cohesion, it is complemented by the importance of sharing emotion that is different from outgroup emotion (Wohl, Hornsey, \& Bennett, 2010). Thus the effects of emotion processes on intragroup processes depend on intergroup processes. Shared emotions also determine the extent to which group members engage in affiliative behaviors directed toward the group (Smith et al., 2007)

Second, the sharing of ingroup emotions has a motivating function when it comes to group action (Barsade \& Knight, 2015; Collins, Lawrence, Troth, \& Jordan, 2013; van Zomeren, Leach, \& Spears, 2012). A meta-analysis of 39 studies of more than 2000 work groups showed that positive group emotions have positive effects on task performance regardless of whether the group is long term or fleeting (Knight \& Eisenkraft, 2015). Positive emotions typically facilitate cooperation, enhance levels of productivity and aggregate task performance, and improve organizational citizenship 
behavior (Menges, Walter, Vogel, \& Bruch, 2011), although these effects can depend on task type and intragroup trust (Williams, 2007). Just as with intergroup relations, the impact of shared negative intragroup emotions on group processes is more complex. Negative emotions can increase task performance early on in groups especially if the source of the affect is external to the group, but tends to undermine performance later in group development, especially if people and events internal to the group generate the negative feelings (Knight \& Eisenkraft, 2015).

\section{Group-based Emotions and Intergroup Relations}

Accepting that emotions operate at the group level has had significant impact on the field's understanding of intergroup relations. First, it provides an alternative to attitudelike conceptualizations of prejudice (negative attitude, dislike) as a driver of intergroup behavior. Knowing what specific emotions one group feel toward another provides more specific information than traditional measures of prejudice. For example, Ray, Mackie, Smith, and Terman (2012) showed that individuals could have very similar evaluative attitudes toward outgroups but very different emotional feelings about them, so that prejudice as typically measured masked many combinations of sometimes conflicting feelings about groups.

Second, specific group-based emotions (in comparison to general positive or negative evaluations) produce readiness for specific forms of discrimination such as harm versus avoidance (Frijda, Kuipers, \& ter Schure, 1989) that are not predictable by an attitudebased approach. There are now extensive literatures showing the predictive value of intergroup anger, fear, and disgust (and their related consequences such as moral exclusion and dehumanization) for specific forms of intergroup conflict (see Iyer \& Leach, 2008; Mackie \& Smith, 2016; Parkinson, Fischer, \& Manstead, 2005 for reviews). For example, both anger and disgust toward an out-group can predict desire to attack that group (Mackie, Devos, \& Smith, 2000). Anger toward an outgroup has been shown to predict support for "normative" forms of confrontation, such as protest and petition signing, whereas disgust appears to justify extreme and aggressive intergroup behavior, such as arson and violent attacks (Tausch et al., 2011). Similar literatures show the role of group-based admiration, warmth, and guilt as emotional precursors of intergroup restitution, repair, and reconciliation (see Mackie \& Smith, 2016, for a review). When German students read that a large German company was to condone cruel working conditions in their overseas suppliers, their group-based guilt predicted their willingness to pay future reparations (Caouette, Wohl, \& Peetz, 2012; Shepherd, Spears, \& Manstead, 2013).

\section{Group-based emotions: The next decade}

The idea that emotions could be a product of group level processes set in motion by categorization and identification has thus proved a remarkably generative one. Not only has it led to theoretical extension of both social psychological and emotion theory, but it has also had practical implications for group functioning, group performance, intergroup conflict, and intergroup reconciliation. What more might we learn about group-based 
emotion in the next decade or so that would continue to advance this agenda? In the remainder of this article we suggest several intriguing questions as potential foci for research and theoretical advancement.

How can group-based emotions best be measured? Despite some intermittent attempts to corroborate the reality of emotional experience (Rydell et al., 2008), most of the groupbased emotion research agenda, like most emotion research in general, relies on selfreported explicit measures. In addition to convenience, this state of affairs is at least partly because, at least by some definitions, there can be no such thing as unconscious emotions and so implicit methods have seemed inapplicable. However, assessing emotions more implicitly may reduce intentional distortion, reducing the selfpresentational concerns that might be activated in group contexts. The most promising techniques may well be emotional adaptations of implicit affect (the IPANAT, Quirin, Kazen, \& Kuhl, 2009) and of well-established social cognition tests of implicit evaluation (the IAT, Egloff, Weck, \& Schmukle, 2008); the AMP, Payne, Cheng, Govorun, \& Stewart, 2005; and stem completion, DeWall \& Baumeister, 2007). One possible avenue is suggested by work from Bartoszek and Cervone (2016), who have shown that ratings of emotion expressed in abstract paintings reflects raters' current acutely induced or chronically activated emotional state(at least sadness, joy, and fear). Another direction worth exploring is implied by embodiment approaches, the idea that emotions are for action. This notion suggests that approach and avoidance movements should be differentially facilitated by the emotions theoretically associated with them. For example, a corroborative measure of fear versus anger should be each emotion's effect on movements toward or away from a target object (Krieglmeyer, Deutsch, De Houwer, \& De Raedt, 2010). Recent demonstrations (Harrison, Gray, Gianaros, \& Critchley, 2010) that a combination of functional magnetic resonance imaging and multi-organ physiological recording can differentiate two different kinds of disgust open the possibility that sophisticated measures may also be able to tap other emotions (see also Kragel \& Labar, 2016).

How is group emotion represented and whose emotions are represented? One potential answer to this question focuses on whether there is anything special about the representation of group emotion that separates it from one's own emotion by identifying it as shared, associated with the group, or consensual in some sense. Is knowledge about how you feel, how another member of your group feels, and how people in your ingroup feel in general represented in different ways, and if so, with what consequences? Very little is known about if or how the consensus or popularity of a particular response is encoded, although people consciously recognize the difference between their individual attitudes and their group's shared norms. Conformity occurs following exposure to group member responses as well as to group norms, and thus perhaps they are not different in their effects. We (Smith \& Mackie, 2016) recently argued that people routinely represent the responses, including the emotional responses, of others who are psychologically salient either acutely (because they are reacting to the same stimulus) or chronically (ingroup members). We assume that such representation is adaptive in situations involving interaction, so that it occurs spontaneously - that is, we imagine, estimate, guess, intuit, or simulate what others feel - even if direct information about their responses is not available. Since ingroup members have enduring psychological 
relevance and are often engaged in similar tasks, this process is highly likely to influence intragroup processes. A further assumption of our model is that representations of one's own responses and those of similar others are easily confusable, providing a means by which one's own responses are influenced by the group. And although ingroups are more likely to trigger representation, outgroups can certainly be psychologically salient, making this mechanisms relevant to intergroup relations as well. Group members not only experience their own emotions but can represent the outgroup's emotions as well (Chen, Moons, \& Mackie, in press; Seger et al., 2009) at least when asked explicitly. Such representations of outgroup emotion help guide behavioral strategies when dealing with an outgroup (Chen et al., in press).

What are the implications of emotion being associated with an identity? One salient way in which emotions differ from familiar concepts like attitudes or stereotypes is that they are dynamic, unfolding over time (Smith \& Mackie, 2015). The fact that emotions derive from an identity rather than from a biological entity provides a unique cause of such fluidity. Shifting from one self-categorization to another (e.g., from "employee of this company" to "union activist”) can change group-based appraisals and/or group-based emotions. With intragroup emotion, shifting roles might have the same outcome. Categorizations and re-categorizations are relatively easily induced by environmental factors (labeling, presence of group symbols or members, group settings, presence of outgroups), so they may well explain some of this natural and constant emotional ebb and flow. This causal link between group membership and emotion also suggests unexplored avenues for self-regulation of emotion and for the activation of categorizations as interventions. Do people understand the role of memberships in changing emotions? When motivated to reduce anger toward an outgroup, might people consciously adopt another role or membership that provides a different emotional reaction? We are used to the plea to "put yourself in their shoes" to change emotional reactions toward outgroups, but might people also benefit from putting themselves in the shoes not of the outgroup, but of another group who reacts differentially to the outgroup? Since different emotional reactions toward the same objects have been found when one identity is made experimentally more salient than another (Ray et al., 2008), the applicability of such changes as interventions, whether self-generated or externally induced, certainly seem worth exploring.

Social identity also allows a role for identification, the extent to which the identity is central and important to the self. And thus changes in an individual's level of identification with a group can similarly contribute to the fluidity of emotions, as well as function as a means of emotion regulation and a probable candidate for intervention. For example, highly identified sports fans may feel anger after a loss while low identifiers instead feel sadness (Crisp, Heuston, Farr, \& Turner, 2007), so group members not wanting to feel angry may mentally back away from the group. Group members who chronically experience negative emotions on behalf of a specific group membership may come to identify less or even dis-identify with that group, perhaps choosing instead to emphasize other self-categorizations that are more emotionally satisfying or rewarding (e.g., Zou, Morris, \& Benet-Martinez, 2008). Who does this, under what circumstances, and why? An important direction for future work is consideration of both potential goals 
that can motivate people to regulate their levels of group identification either upward or downward, and potential processes that can be engaged for those purposes.

In one relevant study (Haupert, Smith, \& Mackie, 2016) we asked participants about their present levels of group identification using Leach et al.'s (2008) measure, and also about their ideal future levels of identification using rewordings of the same items. One general pattern was that ideal levels of self-investment (commitment to the group, importance and centrality of the group) were often higher than reported present self-investment. In contrast, self-definition (perceived similarity of the self and other group members) was generally lower as an ideal than at present. This pattern may give insights into the type of group identification that people desire and may seek to attain. Another finding was that ideal future identification predicted some forms of group-relevant behavior above and beyond prediction from reported present levels. Such results suggest motivated regulation of group identification, as group members shift their behavior seemingly in an effort to increase (or decrease) their group identification from its present level to a more ideal level.

How can changes in group-based emotion reduce conflict within and between groups? Active regulation of emotion has long been studied at the individual level, and recent theoretical advances acknowledge that regulation can occur at the group level as well (Goldenberg, Halperin, Van Zomeren, \& Gross, 2015). Regulation of group-based emotions can involve similar strategies as those at the individual level (Gross \& Thompson, 2007; Goldenberg et al., 2015). Both self-regulation and externally imposed interventions can use four general strategies to change conflict-related emotions and thus reduce - or exacerbate - conflict: people can choose to enter or avoid emotion-inducing situations, deploy attention to specific features of a situation, appraise the features that are attended, or modify their emotional responses (e.g., by suppressing emotion expression). In a group situation emotions might be regulated by deliberately directing one's attention to other group members' or to an outgroup's emotional expression to help regulate emotions. For examples, leaders have been found to have a predominant influence on intragroup emotion (Barsade \& Knight, 2015) and so paying disproportionate attention to leaders might be particularly effective. Uniquely from the group-based emotion perspective, such activities are not only self-regulatory but groupregulatory. When one group member attends to the positive aspects of an event, or reappraises and thus expresses satisfaction instead of guilt, or suppresses glee even while experiencing it, contagion and normative processes make it more likely that others do the same.

Behavior in any given group situation might also be regulated by ideal levels of particular emotions (Porat, Halperin, \& Tamir, 2016). For example, members of a group might particularly want to lower their levels of guilt after their group commits a negative act (e.g., attempts to target enemy forces kill many civilians). Or they might want to experience high levels of fear, to maintain and increase their group's commitment to group affiliative behavior. Evidence from studies by Porat et al. (2016), often based on intense intergroup situations such as the Israeli-Palestinian conflict, shows that group members' ideal levels of particular emotions can be measured or manipulated, and that 
ideal levels at one point in time predict actually reported levels of emotion at a later time. Focus on future versus past emotions may similarly be used as self-regulatory strategies both to change current emotion states and to motivate particular behaviors. Spanovic, Lickel, Denson, and Pertrovic (2010) showed that when group members focused on the future, intergroup fear motivated aggression, but when they focused on the past, it was their anger that motivated aggression. Such findings, as well as the idea that the anticipation of future emotional states drives behavior (Baumeister et al., 2007) provide obvious potential strategies for emotional and behavioral regulation.

What about group-based emotion drives behavior? A bedrock assumption of the individual emotion approach is that emotions about an object drive our behavior toward it. Consideration of group-based emotion, however, makes clear the equal importance of the identity for generating the emotion: the same goal may trigger different emotions depending on the current ingroup-based emotion; the same outgroup may trigger different emotions depending on the current group categorization. Considering a group, rather than the target of the emotion, as the locus of emotions has led to the question of whether it is emotions toward a relevant outgroup, as is customarily assumed, or emotions about the ingroup itself, that drives intergroup behavior. Framed in terms of attitudes, the parallel question of whether ingroup love or outgroup hate drives discrimination has been addressed (Brewer, 1999; Greenwald \& Pettigrew, 2014). We have long appreciated that feelings about an outgroup can influence intragroup behavior as much as feelings about the ingroup (the effect of intergroup conflict on intragroup cooperation, for example; Bornstein, 2003). The idea that feelings about the ingroup could influence intergroup behavior as much as feelings about the outgroup opens many avenues for research exploration.

\section{Conclusion}

The number of questions raised by the current state of the group-based literature - and these are only some of them - seems to bode well for continued generativity and productivity in the area. At heart, the success of group-based emotion in predicting intragroup and intergroup behavior provides support for a more general emerging change way from egocentrism in social psychology (Mesquita, Barrett, \& Smith, 2010). We are used to thinking that our internal beliefs, preferences, and emotions dictate our behavior, a view supported by most social psychological theorizing. But the pervasive, unconscious, and often unrecognized influence of others is being regularly demonstrated across domains (Chui, Gefland, Yamagishi, Shteynberg, \& Wan, 2010; Kovacs, Teglas,

\& Endress, 2010; Shteynberg, Gelfand, \& Kim, 2009; Smith \& Mackie, 2016; Zou et al., 2009). When emotions arise from and are tied to the social context, the distinction between the individual and the group blurs. 


\section{References}

Abrams, D., \& Hogg, M. A. (1998). Prospects for research in group processes and intergroup relations. Group Processes \& Intergroup Relations, 1, 7-20.

Barsade, S. G., \& Gibson, D. E. (1998). Group emotion: A view from top and bottom. In D. Gruenfeld, B. Mannix, \& M. Neale (Eds.), Research on managing on groups and teams (pp. 81-102). Stamford, CT: JAI.

Barsade, S. G., \& Gibson, D. E. (2012). Group affect: Its influence on individual and group outcomes. Current Directions in Psychological Science, 21, 119-123. doi: 10.1177/0963721412438352

Barsade, S. G., \& Knight, A. P. (2015). Group affect. Annual Review of Organizational Psychology and Organizational Behavior, 2, 14.1-14.26. doi:10.1146/annurevorgpsych-032414-111316

Bartoszek, G. \& Cervone, D. (2016). Toward an implicit measure of emotions: ratings of abstract images reveal distinct emotional states. Cognition \& Emotion, 7, 1-15.

Baumeister, R. F Vohs, K., D Dewall, N \& Zhang, L. (2007). How emotion shapes behavior: Feedback, anticipation, and reflection, rather than direct causation. Personality and Social Psychology Review, 2, 167-203. doi: 10.1177/1088868307301033

Branscombe, N. R., Schmitt, M. T., \& Harvey, R. D. (1999). Perceiving pervasive discrimination among African Americans: Implications for group identification and well-being. Journal of Personality and Social Psychology, 77, 135.

Caouette, J., Wohl, M. J. A., \& Peetz, J. (2012). The future weighs heavier than the past: Collective guilt, perceived control and the influence of time. European Journal of Social Psychology, 42, 363-371. doi:10.1002/ejsp.1857

Chen, J., Moons, W.G., \& Macke, D.M. (in press). Stereotypes: A source of Bias in Affective and Empathic Forecasting. Group Processes \& Intergroup Relations.

Chiu, C., Gelfand, M. J., Yamagishi, T., Shteynberg, G., \& Wan, C. (2010). Intersubjective culture: The role of intersubjective perceptions in cross-cultural research. Perspectives on Psychological Science, 5, 482-493. doi:10.1177/1745691610375562

Collins, A. L., Lawrence, S. A., Troth, A. C., \& Jordan, P. J. (2013). Group affective tone: A review and future research directions. Journal of Organizational Behavior, 34, S43-S62. doi: 10.1002/job.188 
Combs, D. J. Y., Powell, C. A. J., Schurtz, D. R., \& Smith, R. H. (2009). Politics, schadenfreude, and in-group identification: The sometimes funny thing about a poor economy and death. Journal of Experimental Social Psychology, 45, 635646. doi:10.1016/j.jesp.2009.02.009

Crisp, R. J., Heuston, S., Farr, M. J., \& Turner, R. (2007). Seeing red or feeling blue: Differentiated intergroup emotions and in-group identification in soccer fans. Group Processes and Intergroup Relations, 10, 9-26. doi:10.1177/1368430207071337

Doosje, B., Branscombe, N. R., Spears, R., \& Manstead, A. S. R. (2006). Antecedents and consequences of group-based guilt: The effects of in-group identification. Group Processes and Intergroup Relations, 9, 325-338. doi:10.1177/1368430206064637

Egloff, B., Weck, F., \& Schmukle, S. C. (2008). Thinking about anxiety moderates the relationship between implicit and explicit anxiety measures. Journal of Research in Personality, 42, 771-778.

Fischer, A. H., Manstead, A. S. R., \& Zaalberg, R. (2003). Social influences on the emotion process. European Review of Social Psychology, 14, 171-201. http://doi.org/10.1080/10463280340000054

Frijda, N. H., Kuipers, P., \& ter Schure, E. (1989). Relations among emotion, appraisal, and emotional action readiness. Journal of Personality and Social Psychology , 57, 212-228. doi:10.1037/0022-3514.57.2.212

Gross, J. J., \& Thompson, R. A. (2007). Emotion Regulation: Conceptual Foundations. In Gross, James J. (Ed). Handbook of emotion regulation (pp. 3-24). New York, NY, US: Guilford Press.

Gawronski, B. and De Houwer, J. (2014). Implicit Measures in Social and Personality Psychology. In H. T. Reis, \& C. M. Judd (Eds.), Handbook of research methods in social and personality psychology (2nd edition). New York: Cambridge University Press.

Goldenberg, A., Halperin, E., Van Zomeren, M., \& Gross, J. J. (2015). The Process Model of Group-Based Emotion: Integrating Intergroup Emotion and Emotion Regulation Perspectives. Personality and Social Psychology, 1-24. http://doi.org/10.1177/1088868315581263

Gordijn, E. H., Yzerbyt, V., Wigboldus, D., \& Dumont, M. (2006). Emotional reactions to harmful intergroup behavior. European Journal of Social Psychology, 36, 1530. doi:10.1002/ejsp.296 
Harrison, N.A., Gray, M.A., Gianaros, P.J., \& Critchley, H.D. (2010). The embodiment of emotional feelings in the brain. Journal of Neuroscience, 30, 12878-2884; DOI: http://dx.doi.org/10.1523/JNEUROSCI.1725-10.2010

Haupert, M., Smith, E. R., \& Mackie, D. M. (2016). Facets of identities over time. Unpublished, Indiana University, Bloomington.

Ilies, R., Wagner, D. T., \& Morgeson, F. P. (2007). Explaining affective linkages in teams: Individual differences in susceptibility to contagion and individualismcollectivism. Journal of Applied Psychology, 92, 1140-1148. doi: 10.1037/00219010.92.4.1140

Iyer, A., \& Leach, C. W. (2008). Emotion in intergroup relations. European Review of Social Psychology, 19, 86-124. doi:10.1080/10463280802079738

Kragel, P.A., \& LaBar, K.S. (2016). Decoding the nature of emotion in the brain. Trends in the Cognitive Sciences, 20, 444-455.

Knight, A. P \& Eisenkraft, N. (2015). Positive is usually good, negative is not always bad: the effects of group affect on social integration and task performance. Journal of Applied Psychology, 100, 1214-1227.

Krieglmeyer, R., Deutsch, R., De Houwer, J, \& De Raedt, R. (2010). Being moved: Valence activates approach-avoidance behavior independently of evaluation and approach-avoidance intentions, Psychological Science, 21, 607-613.

Leach, C. W., van Zomeren, M., Zebel, S., Vliek, M., Pennekamp, S. F., Doosje, B., ... Spears, R. (2008). Group-level self-definition and self-investment: A hierarchical (multi-component) model of ingroup identification. Journal of Personality and Social Psychology, 95, 144-165. doi:10.1037/0022-3514.95.1.144

Livingstone, A. G., Spears, R., Manstead, A. S. R., Bruder, M., \& Shepherd, L.(2011). We feel, therefore we are: Emotion as a basis for selfcategorization and social action. Emotion, 11, 754-767. doi: 10.1037/a0023223

Mackie, D. M., Devos, T., \& Smith, E. R. (2000). Intergroup emotions: Explaining offensive action tendencies in an intergroup context. Journal of Personality and Social Psychology, 79, 602-616. doi:10.1037/0022-3514.79.4.602

Mackie, D.M., \& Smith, E.R. (2016). Intergroup Emotions. In J.F Dovidio and J.A. Simpson (Ed). (2015). APA handbook of personality and social psychology (Vol. 2, Group processes, pp. 263-293). Washington, DC, US: American Psychological Association. http://dx.doi.org/10.1037/14342-010

Maitner, A. T., Mackie, D. M., \& Smith, E. R. (2007). Antecedents and consequences of satisfaction and guilt following in-group aggression. Group Processes and 
Intergroup Relations, 10, 223-237. doi:10.1177/1368430207075154

Mengus, J. I., \& Kilduff, M. (2015). Group emotions: Cutting the Gordian Knots concerning terms, levels of analysis, and processes. The Academy of Management Annals, 9, 845-928.

Menges, J. I., Walter, F., Vogel, B., \& Bruch, H. (2011). Transformational leadership climate: Performance linkages, mechanisms, and boundary conditions at the organizational level. The Leadership Quarterly, 22, 893-909.

doi: 10.1016/j.leaqua.2011.07.010

Moons, W. G., Leonard, D. J., Mackie, D. M., \& Smith, E. R. (2009). I feel our pain: Antecedents and consequences of emotional self-stereotyping. Journal of Experimental Social Psychology, 45, 760-769. doi:10.1016/j.jesp.2009.04.016

Niedenthal, P. M., \& Brauer, M. (2012). Social functionality of human emotion. Annual Review of Psychology, 63, 259-285. doi:10.1146/annurev.psych.121208.131605

Parkinson, B., Fisher, A. H., \& Manstead, A. S. R. (2005). Emotion in social relations: Cultural, group, and interpersonal processes. New York, NY: Psychology Press.

Payne, B. K., Cheng, C. M., Govorun, O., \& Stewart, B. D. (2005). An inkblot for attitudes: Affect misattribution as implicit measurement. Journal of Personality and Social Psychology, 89, 277-293. doi:10.1037/0022-3514.89.3.277.

Pennekamp, S. F., Doosje, B., Zebel, S., \& Fischer, A. H. (2007). The past and the pending: The antecedents and consequences of group-based anger in historically and currently disadvantaged groups. Group Processes and Intergroup Relations, 10, 41-55. doi:10.1177/1368430207071339

Porat, R., Halperin, E., \& Tamir, M. (2016). What we want is what we get: Group-based emotional preferences and conflict resolution. Journal of Personality and Social Psychology, 110, 167-190. http://doi.org/10.1037/pspa0000043

Quirin, M., Kazén, M., \& Kuhl J. (2009). When nonsense sounds happy or helpless: The Implicit Positive and Negative Affect Test (IPANAT). Journal of Personality and Social Psychology, 97, 500-16. doi: 10.1037/a0016063.

Ray, D. G., Mackie, D. M., Smith, E. R., \& Terman, A. (2012). Discrete emotions elucidate the effects of crossed-categorization on prejudice. Journal of Experimental Social Psychology, 48, 55-69. doi:10.1016/j.jesp.2011.07.011

Ray, D. G., Mackie, D. M., Rydell, R. J., \& Smith, E. R. (2008). Changing categorization of self can change emotions about out-groups. Journal of Experimental Social Psychology, 44, 1210-1213. doi:10.1016/j.jesp.2008.03.014 
Reyson, S., \& Branscombe, N. R. (2008). Belief in collective emotions as conforming to the group. Social Influence, 3, 171-188. doi:10.1080/15534510802247438

Rydell, R. J., Mackie, D. M., Maitner, A. T., Claypool, H. M., Ryan, M., \& Smith, E. R. (2008). Arousal, processing, and risk taking: Consequences of intergroup anger. Personality and Social Psychology Bulletin, 34, 1141-1152.

Seger, C. R., Smith, E. R., Kinias, Z., \& Mackie, D. M. (2009). Knowing how they feel: Perceiving emotions felt by out-groups. Journal of Experimental Social Psychology, 45, 80-89. doi:10.1016/j.jesp.2008.08.019

Shepherd, L., Spears, R., \&Manstead, A. S. R. (2013b). 'This will bring shame on our nation': The role of anticipated group-based emotions on collective action.Journal of Experimental Social Psychology, 49, 42-57.

Smith, E. R. (1993). Social identity and social emotions: Toward new conceptualizations of prejudice. In D. M. Mackie \& D. L. Hamilton (Eds.), Affect, cognition, and stereotyping: Interactive processes in group perception (pp. 297-315). San Diego, CA: Academic Press.

Smith, E.R., \& Mackie, D.M. (2016). Representation and Incorporation of Close Others' Responses: The RICOR Model of Social Influence. Personality and Social Psychology Review 1-21. DOI: 10.1177/1088868315598256

Smith, E. R., Seger, C. R., \& Mackie, D. M. (2007). Can emotions be truly group level? Evidence for four conceptual criteria. Journal of Personality and Social Psychology, 93, 431-446. doi:10.1037/0022-3514.93.3.431

Spanovic, M., Lickel, B., Denson, T., \& Petrovic, N. (2010). Fear and anger as predictors of motivation for intergroup aggression: Evidence from Serbia and Republika Srpska. Group Processes and Intergroup Relations, 13, 725-739. doi:10.1177/1368430210374483

Tausch, N., Becker, J. C., Spears, R., Christ, O., Saab, R., Singh, P., \& Siddiqui, R. N. (2011). Explaining radical group behavior: Developing emotion and efficacy routes to normative and nonnormative collective action. Journal of Personality and Social Psychology, 101, 129-148. doi:10.1037/a0022728

Thomas, E. F., McGarty, C., \& Mavor, K. I. (2009). Aligning Identities, Emotions, and Beliefs to Create Commitment to Sustainable Social and Political Action. Personality and Social Psychology, 13, 194-218. http://doi.org/10.1177/1088868309341563

Van Zomeren, M., Leach, C. W., \& Spears, R. (2012). Protesters as "Passionate Economists": A dynamic dual pathway model of approach coping with collective 
disadvantage. Personality and Social Psychology, 16, 180-199.

http://doi.org/10.1177/1088868311430835

Walter, F., \& Bruch, H. (2008). The positive group affect spiral: A dynamic model of the emergence of positive affective similarity in work groups. Journal of Organizational Behavior, 29, 239-261. doi: 10.1002/job.505

Williams, M. (2007). Building genuine trust through interpersonal emotion management: A threat regulation model of trust and collaboration across boundaries. Academy of Management Review, 32, 595-621. doi:10.5465/AMR.2007.24351867

Wohl, M. J. A., Hornsey, M. J., \& Bennett, S. H. (2012). Why group apologies succeed and fail: Intergroup forgiveness and the role of primary and secondary emotions. Journal of Personality and Social Psychology, 102, 306-322. doi:10.1037/a0024838

Yzerbyt, V., \& Kuppens, T. (2009). Group based emotions: The social heart in the individual head. In S. Otten, K. Sassenberg, \& T. Kessler (Eds.), Intergroup relations: The role of motivation and emotion (pp. 143-161). New York, NY: Psychology Press.

Zou, X., Morris, M. W., \& Benet-Martínez, V. (2008). Identity motives and cultural priming: Cultural (dis) identification in assimilative and contrastive responses. Journal of Experimental Social Psychology, 44, 1151-1159.

Zou, X., Tam, K., Morris, M. W., Lee, S., Lau, I. Y. M., \& Chiu, C. (2009). Culture as common sense: Perceived consensus versus personal beliefs as mechanisms of cultural influence. Journal of Personality and Social Psychology, 97, 579-597. 